Gut, 1978, 19, 794-797

\title{
Increased serum immunoreactive gastrin levels in idiopathic hypertrophic pyloric stenosis ${ }^{1}$
}

\author{
M. A. BLEICHER ${ }^{2}$, B. SHANDLING, W. ZINGG, H. W. A. KARL, AND \\ N. S. TRACK \\ From the Division of General Surgery, Department of Surgery, University of Toronto, \\ The Hospital for Sick Children and Mount Sinai Hospital, Toronto, Ontario, Canada, and \\ Department of Surgery, Health Sciences Centre, McMaster University, Hamilton, Ontario, Canada
}

SUMMARY The serum immunoreactive gastrin (IRG) level in infants with confirmed idiopathic hypertrophic pyloric stenosis (IHPS) has been determined and compared to that found in vomiting infants without IHPS, in normal infants, and in normal adults. The mean serum IRG level of normal infants $(103 \pm 9 \mathrm{pg} / \mathrm{ml}$ (mean \pm SEM) exceeded that of normal adults $(28 \pm 5 \mathrm{pg} / \mathrm{ml})$. The preoperative mean serum IRG level in IHPS infants $(256 \pm 26 \mathrm{pg} / \mathrm{ml})$ was significantly higher than that of both normal infants and vomiting infants without IHPS $(93 \pm 9 \mathrm{pg} / \mathrm{ml})$. Twenty-five per cent $(5 / 20)$ of the IHPS infants had serum IRG levels within the upper range of normal infants. Fasting serum IRG levels in IHPS infants were not altered immediately by pyloromyotomy. The results from this study suggest a relationship between gastrin and idiopathic hypertrophic pyloric stenosis.

Although the pathological and anatomical changes accompanying idiopathic hypertrophic pyloric stenosis (IHPS) are well documented, the aetiology and pathogenesis of this condition are unknown. Several studies (Dodge, 1970; Karim et al., 1974; Dodge and Karim, 1976) have demonstrated that when pentagastrin injections were administered to pregnant bitches their offspring developed hypertrophic pyloric stenosis; this finding prompted a hypothesis that gastrin is an aetiological factor in human IHPS (Dodge, 1972; Dodge and Karim, 1976). At present, the status of the gastrin hypothesis in human IHPS is uncertain because evidence has been presented both to support (Spitz and Zail, 1976) and refute (Rogers et al., 1975) it. No systematic evaluation of fasting and postprandial serum IRG levels in infants has been undertaken to establish the normal fasting and stimulated ranges of IRG. Available evidence indicates that a neonatal hypergastrinaemia does exist (Rogers et al., 1974; Sann et al., 1975; Euler et al., 1977).

${ }^{1}$ Presented in part at the Combined Centennial Meeting of The Hospital for Sick Children Medical Alumni, Toronto, Ontario, Canada, June 1975.

${ }^{2}$ Address for correspondence: Dr M. A. Bleicher, Chief, Division of Pediatric Surgery, The Mount Sinai Hospital, Fifth Avenue and 100th Street, New York, NY, USA 10029.

Received for publication 29 March 1978
A number of different serum IRG components with varying molecular size have been found in adults (cf. Walsh, 1977). It is claimed that $45 \%$ of neonatal serum IRG is 'big-big' gastrin (Torsoli et al., 1975).

The present study examines serum immunoreactive gastrin (IRG) levels pre- and postoperatively in a group of infants with confirmed IHPS. These values have been compared to those found in vomiting infants without IHPS, in normal infants, and in normal adults. In addition, the distribution of serum IRG components has been studied by Sephadex G-50 gel chromatography in preoperative IHPS and normal infants' samples.

\section{Methods}

\section{SUBJECTS}

Fasting venous blood samples were obtained from 20 infants with IHPS preoperatively, from five vomiting infants without IHPS, from 18 normal infants hospitalised for elective procedures-for example, hernia repair, circumcision, congenital dislocated hip repair-and from 20 normal adults. The diagnosis of idiopathic hypertrophic pyloric stenosis (IHPS) was made on clinical history and by palpation of the pyloric mass; this diagnosis was confirmed at operation in all 20 infants. Oral gastric aspiration of the stomach was performed in the operating room before the induction of anaesthesia. Less than $25 \mathrm{ml}$ of 
mucoid gastric contents ( $\mathrm{pH} 6.0$ ) were aspirated from each infant's stomach. Five other infants with projectile vomiting but no palpable pyloric mass underwent barium study to confirm the absence of pyloric stenosis.

\section{BLOOD SAMPLING}

Blood samples were obtained from all IHPS and vomiting infants after at least a 12 hour fast. None of the infants had received any preoperative medication before the blood sampling. Intravenous infusions were running during this period; the nature and volume of solution selected for infusion were based upon the severity of the electrolyte abnormality and clinical status of hydration in each particular infant. Infants received the following solutions: $5 \%$ dextrose together with normal saline, one-half strength saline or one-quarter strength saline; each solution was supplemented with $5 \mathrm{mmol} \mathrm{KCl} / 250 \mathrm{ml}$. No attempt was made at nasogastric decompression. All infants studied with barium had blood samples obtained before the barium study. Sixteen to 80 hours after pyloromyotomy, when at least three formula (Enfalac) feedings had been tolerated without vomiting, a fasting blood sample was taken from seven of the IHPS infants. The blood was drawn just before the next scheduled feeding four hours later as this constituted the longest fasting period in infants of this age. Normal infants' blood was taken also four hours after formula (Enfalac) feeding with or without cereal (Pablum). Blood from normal adults was obtained after an overnight fast. From all test groups venous blood was collected, allowed to clot, centrifuged, and the serum stored at $-20^{\circ} \mathrm{C}$. Serum immunoreactive gastrin (IRG) level was determined in duplicate by a gastrin radioimmunoassay described eleswhere in detail (Mayer et al., 1974).

\section{GEL CHROMATOGRAPHY}

Three sera from preoperative IHPS infants and three from normal infants were chromatographed upon a Sephadex G-50F column $(1.0 \times 200.0 \mathrm{~cm})$ in $0.2 \mathrm{M}$ $\mathrm{NH}_{4} \mathrm{HCO}_{3}$. The column was calibrated with natural, human G-34 and G-17; the gastrin components were gifts from Professor R. A. Gregory, Liverpool. Serum volumes applied ranged from 0.5-1.2 ml. One millilitre consecutive fractions were collected commencing just before the void volume $(40 \mathrm{ml})$ and finishing at the excluded volume $(140 \mathrm{ml})$. All column fractions were lyophilised and odd-numbered tubes assayed with antibody for IRG content and evennumbered tubes assayed without antibody for the unspecific binding. The average IRG recovery from the column was $88 \%$.

Statistical evaluation of the data was performed by Student's $t$ test. This project was approved by the
Scientific and Ethics Committee of The Hospital for Sick Children, Toronto, and written consent was obtained from parents of all test subjects.

\section{Results}

The numbers, sex distribution, and age of the groups studied are listed in Table 1 . Since no differences existed between male and female serum IRG values, all values in each group were pooled for the calculations. The mean fasting serum IRG values for the normal adults, normal infants, preoperative IHPS infants, and vomiting infants without IHPS are shown in Fig. 1. Normal infants showed a significant rise of serum IRG above the adult value $(P<0.001)$; the preoperative IHPS infants showed a further significant increase above both the normal infant $(P<0.001)$ and adult values $(P<0.001)$. The serum IRG in vomiting infants without IHPS, although above the adult values, was significantly lower than the preoperative IHPS infants $(P<0.001)$.

Table 1 Number, sex distribution, and age of study groups

\begin{tabular}{|c|c|c|c|c|}
\hline \multirow[t]{2}{*}{ Group } & \multirow[t]{2}{*}{ Number } & \multicolumn{2}{|l|}{ Sex } & \multirow{2}{*}{$\begin{array}{l}\text { Age } \\
\text { (days) }\end{array}$} \\
\hline & & Male & Female & \\
\hline $\begin{array}{l}\text { Normal infants } \\
\text { IHPS* infants }\end{array}$ & 18 & 14 & 4 & $2-98$ \\
\hline Preoperative & 20 & 15 & 5 & $17-95$ \\
\hline Postoperative & 7 & 4 & 3 & $22-70$ \\
\hline Vomiting infants & 5 & 5 & 0 & $9-60$ \\
\hline Normal adults & 20 & 14 & 6 & $18-37 \mathrm{yr}$ \\
\hline
\end{tabular}

*Idiopathic hypertrophic pyloric stenosis.

The age distribution of serum IRG levels in IHPS and normal infants is illustrated in Fig. 2. Normal infants' levels ranged from $25-162 \mathrm{pg} / \mathrm{ml}$; IHPS infants' from $115-623 \mathrm{pg} / \mathrm{ml}$. Five of the IHPS infants' levels were within the upper range of normal infants. IHPS infants' pre and postoperative fasting serum IRG levels were not significantly different (Table 2).

Sephadex G-50 gel chromatography of three preoperative IHPS and three normal infants' sera revealed one major IRG peak having an IRG elution profile comparable to G-34. A representative Sephadex G-50 elution profile is presented in Fig. 3. No significant IRG activity was detected in the void volume of the column, the elution position of 'bigbig' gastrin. The unspecific binding was comparable across the column fractions and not different from the unspecific binding of the gastrin radioimmunoassay. 


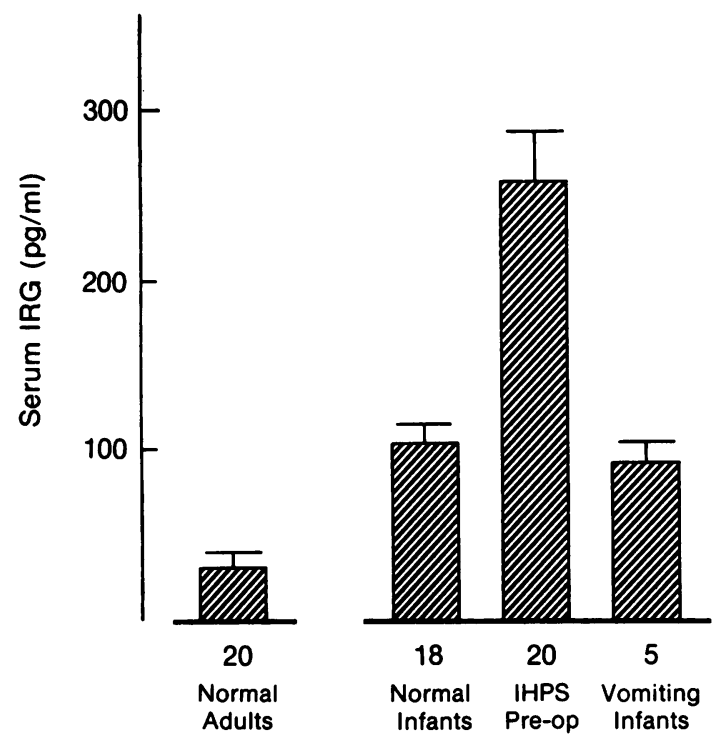

Fig. 1 Comparison of mean $( \pm S E M)$ fasting immunoreactive gastrin (IRG) levels found in normal adults, in normal infants, in infants with idiopathic hypertrophic pyloric stenosis preoperatively (IHPS Pre-op), and in infants who vomit without IHPS (vomiting infants).

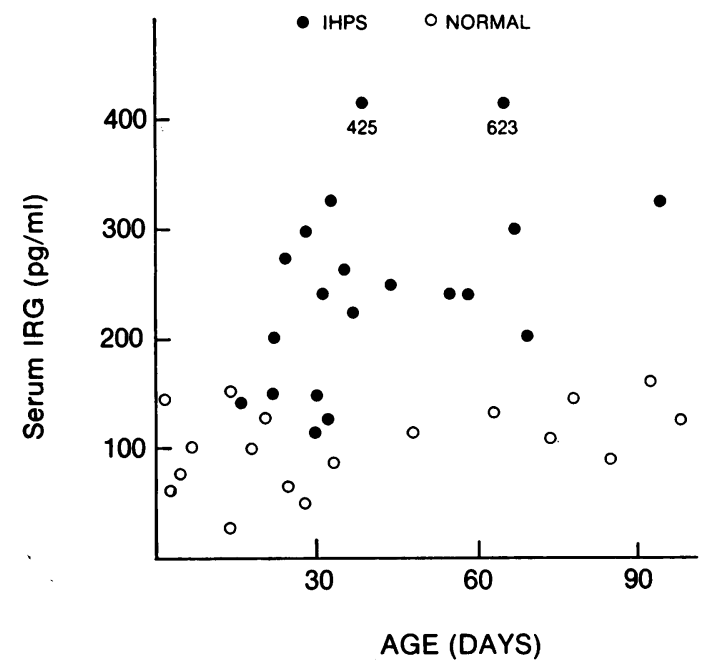

Fig. 2 Age distribution of serum immunoreactive gastrin (IRG) levels in preoperative infants with idiopathic hypertrophic pyloric stenosis and in normal infants.

\section{Discussion}

The results of this study confirm the presence of neonatal hypergastrinaemia (Rogers et al., 1974; Sann et
Table 2 IHPS* infants: Pre and postoperative mean fasting serum immunoreactive gastrin (IRG) levels

\begin{tabular}{lll}
\hline & Number & $\begin{array}{l}I R G(p g / m l) \\
(m \pm S E M)\end{array}$ \\
\hline Preoperative & 20 & $256 \pm 26$ \\
Postoperative & 7 & $228 \pm 30$ \\
\hline
\end{tabular}

*Idiopathic hypertrophic pyloric stenosis.

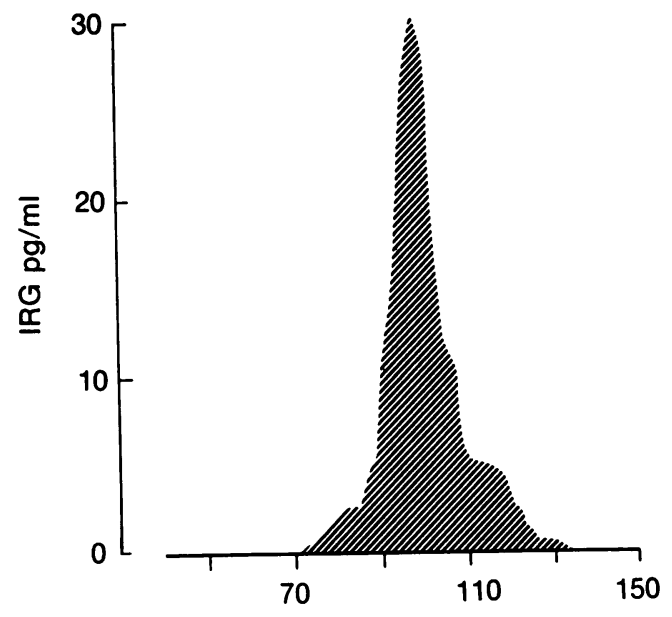

FRACTION NUMBER

Fig. 3 A representative Sephadex $G-50$ immunoreactive gastrin (IRG) elution profile of a preoperative IHPS infant's serum. Major IRG peak corresponds to the elution position of $G-34$.

al., 1975; Euler et al., 1977) and provide evidence for an even greater rise in most infants with idiopathic hypertrophic pyloric stenosis (IHPS). The raised serum IRG is not due to age differences between the IHPS and normal infants because both groups have comparable age distributions and within this range no effect of age upon the IRG levels was observed (Fig. 2). Furthermore, the immediate preoperative aspiration of mucoid gastric contents eliminates the possibility of residual food in the stomach causing the raised serum IRG in the IHPS infants. Pyloromyotomy has no immediate effect upon fasting serum IRG levels indicating that the pyloric stenosis is not the cause of the raised serum IRG.

The Sephadex G-50 IRG elution profiles reveal that G-34 is the major circulating IRG component in the neonatal sera examined. No evidence was found to support the claim of $45 \%$ 'big-big' gastrin in neonatal sera (Torsoli et al., 1975).

A controversy exists as to whether or not serum IRG is raised in IHPS infants (normal-Rogers $e t$ al., 1975; raised-Spitz and Zail, 1976). From a 
consideration of the available data this discrepancy can be resolved. First, how long was the preoperative fasting period before the blood sample was drawn and how were the infants treated during this time? In the present study, blood samples were drawn from IHPS infants after at least a 12 hour fast during which time the infants were on intravenous fluids; normal infants' blood was drawn after a four hour fast. In the other studies, blood sampling was performed on the IHPS infants 'three hours after their last feed' (Rogers et al., 1975) and 'immediately preoperatively after a six hour fast' (Spitz and Zail, 1976). In these two reports, nothing is mentioned about the infants' preoperative clinical care.

The second and probably most important consideration is the comparison of mean serum IRG levels from normal and IHPS infants. These data are informative but also are misleading! In the present study, there is a significant $(\mathrm{P}<0.001)$ rise of serum IRG in the IHPS infants $(256 \pm 26 \mathrm{pg} / \mathrm{ml})$ compared to the normal infants $(103 \pm 9 \mathrm{pg} / \mathrm{ml})$; however, $25 \%$ $(5 / 20)$ of the IHPS infants have serum IRG levels within the upper range of the normal infants (Fig. 2). In another published series, $50 \%(9 / 18)$ of the IHPS infants have serum IRG levels within the upper range of the normal infants (Spitz and Zail, 1976). This overlap of serum IRG levels between IHPS and normal infants is probably the major reason for the current controversy about serum IRG levels in IHPS.

A recent report in which gastrin is shown to have a direct effect upon pyloric smooth muscle contraction (Rogers et al., 1976) supports the gastrin hypothesis in IHPS. Results from the present study, revealing higher serum gastrin levels in most IHPS infants compared to normal infants, further support a role for gastrin in human IHPS.

The authors acknowledge the technical assistance of Miss Helen McLeod and thank Dr C. A. Stephens, Dr J. S. Simpson, and Dr S. H. Ein for the opportunity to study their patients. This study was supported in part by the Atkinson Charitable Foundation, The Hospital for Sick Children Foundation, and the Canadian MRC (DG 130).

\section{References}

Dodge, J. A. (1970). Production of duodenal ulcers and hypertrophic pyloric stenosis by administration of pentagastrin to pregnant and newborn dogs. Nature, 225, 284285.

Dodge, J. A. (1972). Psychosomatic aspects of infantile pyloric stenosis. Journal of Psychosomatic Research, 16, 1-5.

Dodge, J. A., and Karim, A. A. (1976). Induction of pyloric hypertrophy by pentagastrin. Gut, 17, 280-284.

Euler, A. R., Byrne, W. J., Cousins, L. M., Ament, M. E., Leake, R. D., and Walsh, J. H. (1977). Increased serum gastrin concentrations and gastric acid hyposecretion in the immediate newborn period. Gastroenterology, 72, 12711273.

Karim, A. A., Morrison, J. E., and Parks, T. G. (1974). The role of pentagastrin in the production of canine hypertrophic pyloric stenosis and pyloroduodenal ulceration. British Journal of Surgery, 61, 327 (Abst.).

Mayer, G., Arnold, R., Feurle, G., Fuchs, K., Ketterer, H., Track, N. S., and Creutzfeldt, W. (1974). Influence of feeding and sham feeding upon serum gastrin and gastric acid secretion in control subjects and duodenal ulcer patients. Scandinavian Journal of Gastroenterology, 9, 703710.

Rogers, I. M., Davidson, D. C., Lawrence, J., Ardill, J., and Buchanan, K. D. (1974). Neonatal secretion of gastrin and glucagon. Archives of Diseases in Childhood, 49, 796-801.

Rogers, I. M., Drainer, I. K., Moore, M. R., and Buchanan, K. D. (1975). Plasma gastrin in congenital hypertrophic pyloric stenosis: a hypothesis disproved? Archives of Diseases in Childhood, 50, 467-471.

Rogers, I. M., Macgillion, F., and Drainer, I. K. (1976). Congenital hypertrophic pyloric stenosis: a gastrin hypothesis pursued. Journal of Pediatric Surgery, 11, 173-176.

Sann, L., Chayvialle, J. A. P., Bremond, A., and Lambert, R. (1975). Serum gastrin level in early childhood. Archives of Disease in Childhood, 50, 782-785.

Spitz, L., and Zail, S. S. (1976). Serum gastrin levels in congenital hypertrophic pyloric stenosis. Journal of Pediatric Surgery, 11, 33-35.

Torsoli, A., Delle Fave, G. F., Melchiorri, P., Sopranzi, N., and Kohn, A. (1975). Neonatal hypergastrinaemia in man (Abstract). Gut, 16, 834.

Walsh, J. H. (1977). Gastrin heterogeneity: biological significance. Federation Proceedings, 36, 1948-1951. 